\section{Open innovation and network dynamics. An analysis of openness of co-patenting collaborations in Florence, Italy}

\author{
Francesco Capone and Niccolò Innocenti \\ Department of Economics and Management, University of Florence, Florence, Italy
}

innovation and network dynamics

Received 29 October 2019 Revised 21 January 2020 20 March 2020 Accepted 22 March 2020

\begin{abstract}
Purpose - The purpose of this paper is to investigate the relational dynamics for innovation and, in particular, the impact of the openness of innovation process on the innovation capacity of organisations in restricted geographical contexts.

Design/methodology/approach - Through a negative binomial regression, the work analyses how the characteristics of the openness of the organisation's innovation process in the period 2004-2010 influence the firm's patent productivity in the following period (2011-2016).

Findings - The breadth of the open innovation $(\mathrm{OI})$ process, here measured by the number of external network ties that an organisation realises for the realisation of its patents, has a positive effect on patent productivity. The depth of the openness, that is, the intensity of external network ties, has an equally positive influence on the innovative performance. However, after a tipping point, the patent productivity tends to decrease, underlining the costs and problems of OI practices.

Research limitations/implications - This study considers only patent collaborations in the city of Florence. Therefore, it focusses on codified innovations and on a single territorial case study.

Practical implications - The results underline the importance of the adoption of OI practices in restricted geographical contexts (such as cities, clusters or industrial districts) but with several limitations. Only collaborating more with others does not foster the organisation's invention productivity, but different types of evidence are found here.

Originality/value - An original database has been created, containing all the information on patents realised in the area of Florence from 2004 until 2016, and a social networks analysis was applied to identify the local innovation networks.
\end{abstract}

Keywords Open innovation, Openness, Co-patenting, Network

Paper type Research paper

\section{Introduction}

In the early 2000s, Chesbrough (2003) coined the term open innovation (OI) to highlight the growing relevance of opening up the innovation development process outside a firm's normal boundaries. Chesbrough (2006) defined OI as:

(c) Francesco Capone and Niccolò Innocenti. Published by Emerald Publishing Limited. This article is published under the Creative Commons Attribution (CC BY 4.0) licence. Anyone may reproduce, distribute, translate and create derivative works of this article (for both commercial and noncommercial purposes), subject to full attribution to the original publication and authors. The full terms of this licence may be seen at http://creativecommons.org/licences/by/4.0/legalcode

The authors express their gratitude to Simone Vannini for data collection.
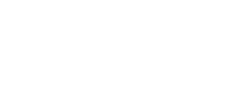
$\mathrm{CR}$ 30,4

[...] the use of purposive inflows and outflows of knowledge to accelerate internal innovation, and expand the markets for external use of innovation, respectively. [This paradigm] assumes that firms can and should use external ideas as well as internal ideas, and internal and external paths to market, as they look to advance their technology.

Since then, the concept of OI has attracted growing interest among innovation management and management scholars and has become one of the most debated topics (Vanhaverbeke et al., 2014; Kovacs et al., 2015).

Within the OI literature, several studies (Laursen and Salter, 2006; Chiang and Hung, 2010; Hwang and Lee, 2010) have investigated the relationship between a firm's degree of openness and its capacity to innovate, highlighting how the adoption of OI practices (Mortara and Minshall, 2011; Capone et al., 2018) has a significant impact on the innovative capacity of organisations. However, very few analyses have investigated the link between the relational dynamics of organisations and their innovation performance.

With this in mind, the aim of the current work is to investigate the relational dynamics for invention and, in particular, the impact of openness of invention process on the invention capacity of organisations. This work investigates the following research question:

$R Q 1$. What is the role of openness of network relationships for invention?

Numerous studies have underlined the relevance of networks in OI (Dittrich and Duysters, 2007; Belussi and Orsi, 2015; Enkel, 2010; Martinez-Torres, 2014; among others). However, the link between these two streams of research is still undervalued (Capone et al., 2018; Capone and Zampi, 2019). The current work aims to contribute to this debate by investigating the opening up of invention processes through firms' network dynamics.

Moreover, the present paper can be placed in the debate regarding OI dynamics in restricted geographical contexts, such as cities, clusters or industrial districts (Cooke, 2005; Simard and West, 2006), and, particularly, it adds to these studies by showing the differences of clustered firms in adopting OI practices, which is a field that is still underinvestigated (Huang and Rice, 2013; D’Ambrosio et al., 2017).

To analyse the relational dynamics in a restricted geographical context, we focussed on the metropolitan area of Florence as a case study, with the creation of an ad hoc database that includes 3,189 patents realised in the period 2004-2016. This is mainly motivated by two reasons. First, knowledge flows and innovations in a cluster are fostered by trust, and when there is trust, there is a greater exchange of knowledge (Porter, 1998). For instance, firms that are in a restricted geographical context, such as a cluster, can have better access to human capital, specialised suppliers and knowledge spillover (Tallman et al., 2004). Second, because the Patent Statistical (PAT-STAT) Database data do not uniquely identify inventors and applicants, a handmade disambiguation of the data was carried out.

The current work focusses on two determinants of the degree of openness of organisations (Laursen and Salter, 2006; Chiang and Hung, 2010; Ferreras-Méndez et al., 2015; etc.):

(1) the external search breadth, which expresses the breadth of openness in terms of the number of external partners involved in the various innovative activities; and

(2) the external search depth, which is understood as the depth of collaboration with every single source (partner) of external knowledge.

The empirical analysis is based on data collected using the PAT-STAT database of the European Patent Office, which contains information on patents developed in European countries.

Using PAT-STAT data, an original database was created, and a social networks analysis was applied to identify the local invention networks. Through a negative binomial regression 
(NBR), the current work analyses the impact of the characteristics of the openness of the organisation's invention process for the period 2004-2010, along with how the breadth and depth of the openness influence the patent productivity in the period 2011-2016.

The results underline the importance of the adoption of OI practices but with several caveats. The mere increase of patenting collaborations with others does not foster an organisation's innovation productivity, but different results are reached when the characteristics of openness are analysed. Both the breadth of the OI process and the depth of the openness have equally positive effects on patent productivity. Nevertheless, after a tipping point, patent productivity tends to decrease, underlining the costs and problems of OI practices.

\section{Open \\ innovation and network dynamics}

381

\section{Theoretical background}

\section{Open innovation and networks in restricted geographical contexts}

There is an increasing amount of studies studying OI in restricted geographical contexts (e.g. clusters and industrial districts). Cooke (2005) has pointed out that OI may partially explain the competitiveness of regional innovation systems; in this view also, Vanhaverbeke (2006) has underlined that firms in regional clusters tend to use more OI practices. Huang and Rice (2013) analysed the role of clusters in boosting OI practices in Europe, finding that a close geographical proximity tends to increase firm-university linkages (Antonietti and Gambarotto, 2018), enhance inter-firm explicit and tacit knowledge flows and lead to comparatively less reliance on internal R\&D.

The cluster benefits of reduced transaction costs, increased trust and reciprocity tend to facilitate the adoption of OI practices. Di Minin and Rossi (2016) described what makes clusters particularly suitable as vehicles of OI. Giusti et al. (2018) analysed the role of OI networks in an Italian high-tech cluster, showing interesting results on how knowledge is locally embedded and exchanged in innovation networks and how knowledge leaks occur.

Vanhaverbeke et al. (2014) stressed that it is important to analyse the role of geographical concentrations in a territory, such as clusters and districts, to understand if they can be a driver to further promote OI, particularly for the dissemination of knowledge and the role of local networks. Simard and West (2006) underlined how the benefits of OI can be better achieved in clusters of companies, research centres, universities and institutions, which constitute a favourable environment for the exchange of knowledge and better collaboration among companies. Finally, they highlighted the potential of integrating social theories and social network analyses in the analysis of collaborative processes in OI.

Moreover, it is not only the structure but also the external links with other places of local knowledge networks that are relevant for innovation (De Noni et al., 2017; Capone et al., 2019). Malmberg and Maskell (2006) and Bathelt et al. (2004) have suggested that knowledge creation in restricted geographical contexts happens thanks to both local and external knowledge flows, such as buzz, local interactions and external global pipelines. However, in the current paper, we mainly focus on local interactions.

In analysing the adoption of OI practice, several authors have focussed on the study of networks and network dynamics (Capone et al., 2018; Capone and Zampi, 2019). Network dynamics are a possible way of adopting an approach to OI, especially when it comes to outbound OI (Dahlander and Gann, 2010). External networking is perhaps one of the most significant dimensions of outbound OI (Huizingh, 2011), either because of the number of studies in this stream of research or the importance of the topic in the context of studies on innovation networks (Powell and Grodal, 2005; Alberti and Pizzurno, 2015; etc.).

The literature on innovation networks started to develop in the 1990s (Powell et al., 1996), and although its origins precede the coining of the term OI, there are several contributions 
$\mathrm{CR}$ 30,4

that have tried to integrate these two streams of research (Chesbrough, 2003; Dittrich and Duysters, 2007; etc.).

However, in the literature, few studies fit in the intersection of these two streams of research (Capone et al., 2018). One of the first contributions here was Dittrich and Duysters's (2007) study, which stated that innovation networks can be used to manage the process of technological change in the corporate environment by presenting a longitudinal case study of an innovation network during its transition from being closed to accepting OI.

Belussi and Orsi (2015) analysed the interconnections among networks, innovation and high-tech environment and underlined that networks are a means of transition towards a more open approach towards innovation, particularly in high-tech sectors. Lee et al. (2010) studied OI practices in small- and medium-sized firms (SMEs), confirming the potential of adopting innovation practices in SMEs and indicating networking as one of the more effective ways of facilitating innovation among small firms.

Finally, Brunswicker and Van de Vrande (2014) explained that a key area in the research on OI in small firms consists of different kinds of networks when SMEs engage in OI; they underlined that because the locus of innovation regularly resides at the network level, OI in SMEs is naturally quite specific and different from large firms.

\section{Hypotheses of the research}

Several authors have focussed on the process of opening up the innovation process outside a firm's boundaries (Henkel, 2009; Belussi et al., 2010; Herzog and Leker, 2010; Chiaroni et al., 2011; Mortara and Minshall, 2011; Enkel and Bader, 2013; Capone et al., 2019; Ferraris et al., 2017). In fact, OI has been analysed in terms of the degree of openness of a firm's innovation processes (Huizingh, 2011). However, Dahlander and Gann (2010) underlined that there are several degrees of openness and that openness produces benefits (Laursen and Salter, 2006, 2014; Knudsen and Mortensen, 2011; Capone et al., 2018).

Chesbrough (2006) originally underlined that adopting OI practices can boost the innovation productivity of firms, and firms adopting OI are generally more innovative than closed innovation organisations. Recent studies have proposed several potential benefits of opening up the innovation process (Parida et al., 2012). Kovacs et al. (2015) displayed a strand of research called "performance-oriented publications" that points out the positive effect of opening up the innovation process in innovation productivity. Greco et al. (2015) gave the empirical evidence that link OI actions and innovation performance.

Huizingh (2011) defined the openness of the innovation process based on either the number and type of partners or the number and degree of the phases of the innovation process. Dahlander and Gann (2010) introduced a taxonomy of openness linked to the direction of this process (inbound and outbound) and to its nature (pecuniary or nonpecuniary).

Lazzarotti and Manzini (2014) analysed openness based on both partner number and type and the phases of the innovation process. Trott and Hartman (2009) underlined that the opening of innovation is not a standard process but instead develops throughout a continuum of cases, depending on the characteristics of the firms and the context in which they operate.

Hence, our first hypothesis is as follows:

H1. The opening of the innovation process will be positively correlated with the innovation productivity of the organisation.

In addition, networking in OI brings not only advantages but also some problems. Jarvenpaa and Wernick (2011) analysed the difficulties of developing networks for OI, pointing out that networks in the context of OI produce more obstacles than other types of networks. 
However, the definition of openness is not unique (Huizingh, 2011). Dahlander and Gann (2010) underlined several definitions and several degrees of openness. In this context, the literature has mainly focussed on the external search breadth and external search depth of openness.

Among the first empirical studies in the field of open search strategies, here measured in terms of breadth and depth, Laursen and Salter (2006) investigated the impact of the breadth and depth of the relationships with external sources of knowledge on the innovative performance of manufacturing companies in the UK. The study showed that (within a certain limit) breadth and depth are positively correlated with innovative performance.

Laursen and Salter's (2006) study represents the starting point from where many other contributions have been developed regarding the openness of companies. Chiang and Hung (2010) described the impact of breadth and depth, respectively, on incremental innovations and radical innovations; they demonstrated that the breadth and depth of the opening are positively correlated with innovation performances.

In addition to breadth and depth, Chen et al. (2011) included the concept of the orientation of external search strategies as the type of partner with which collaborations are established and how this affects the ability to innovate inside companies. The authors highlighted that the breadth and depth of the relationships positively influence the innovative performances and that the identity of the partners determines a better result in terms of innovation.

Martinez et al. (2014) explored the role of firms' internal organisational variables and external context variables as the two main forces that determine the level of a company's openness. The authors pointed out that both breadth and depth have a positive impact on innovative performances.

Finally, Ferreras-Méndez et al. (2015) analysed the link between opening strategies and absorptive capacity on both innovative and business performance. The results show that there is no link between depth and breadth and innovative and business performance. The intensity of the relationships is positively correlated with the level of absorptive capacity, which, in turn, positively influences innovative and business performance.

In conclusion, all these contributions regarding breadth and depth show a positive influence of these variables on the innovative performance of a firm. Therefore, pursuing openness strategies may produce a higher performance and a competitive advantage for companies that innovate. Having more links increases the likelihood of obtaining useful external knowledge that can be combined with the internal knowledge of the company to produce innovation:

H2.1. The breadth will be positively correlated with the innovation productivity of the organisation.

H2.2. The depth will be positively correlated with the innovation productivity of the organisation.

However, several studies (Laursen and Salter, 2006; Hwang and Lee, 2010; Chen et al., 2011) have shown that there is a curvilinear impact of breadth and depth on innovation. Laursen and Salter (2006) showed that only within a certain limit are breadth and depth positively correlated with innovative performance. Beyond a certain tipping point limit, they generate a negative impact on the innovative performance of the firm.

The main reasons behind this are related to the fact that $R \& D$ is expensive and that managing external relations can be costly. In addition, it is expensive to realise the appropriate contractual arrangements for many external channels and to maintain these links over time (Laursen and Salter, 2006).

Even when formal contractual issues do not arise, there may be other situations that can limit the ability of a company to have a high level of openness. These are derived from the 
$\mathrm{CR}$ 30,4

management's ability to manage many sources of information. These reasons can lead to situations where, at first, the returns from partnerships are positive, but if the level of openness increases too much, the results decrease:

H3.1. The breadth will have a curvilinear relation (taking an inverted U shape) with the innovation productivity of the organisation.

H3.2. The depth will have a curvilinear relation (taking an inverted U shape) with the innovation productivity of the organisation.

\section{Research design}

The empirical analysis is based on data collected using the PAT-STAT database, which contains information on patents developed in the European countries.

From the PAT-STAT database, all the patents filed for in Italy in the period available (2004-2016) were collected (about 68,000 patents). After that, a selection was made, creating an ad hoc database that included 3,189 patents involving at least one inventor in the metropolitan area of Florence for more than 10 years (2004-2016). This was done deliberately disregarding the location of the patent applicant (Ter Wal, 2014). Large companies usually assign patents to their headquarters, even when the patent is developed in one of the company's subsidiaries. Notwithstanding the possibility that some inventors might live in another region than where they work, inventor location is generally agreed to be a more reliable approximation of where the invention was developed (Acs et al., 2002; Ejermo and Karlsson, 2006). Patents developed exclusively by inventors who do not belong to the Province of Florence were excluded from the analysis.

The focus of the database on Florence was also because PAT-STAT data on inventors and applicants are not disambiguated; therefore, inventors and applicants are not univocally identified[1]. In fact, two or more different inventors with the same name could be unified as one individual. Moreover, often both the inventor and the applicant are transcribed incorrectly and with heterogeneous information[2].

Each patent was then analysed by carrying out a handmade disambiguation process both on the inventor and on the applicant of the patent. Each patent was searched and verified, controlling for the inventors and applicants and assigning an ID to each individual or firm. Therefore, in the final database, each inventor (or applicant) uniquely identifies an individual (or a firm).

The final database is composed of 538 applicants (firms, research centres, universities and inventors) who realised 3,189 patents in the studied period[3].

Furthermore, to perform the analysis of the organisations' relational dynamics, the database was organised in a functional way using a social network analysis (Scott, 2011), here with the aim of focussing on the inter-organisational relationships derived from collaborations for the realisation of the patents.

The data for the relational analysis were here elaborated, starting from the applicant $x$ inventor matrix that configures a bipartite (two-mode) network in which the rows indicate the applicants that registered the patent and the columns indicate the inventors. The unipartite (one-mode) network was then obtained from the previous matrix with the transformation of the applicant $\times$ inventor matrix into the applicant $\times$ applicant comembership network (Scott, 2011). Now, the ties between the nodes indicate the number of patents to which the couple of applicants participate together (sharing the same inventors).

At this point, it was possible to use UCINET software for a graphic representation of the innovation networks with graphs (Figures 2 and 3). 


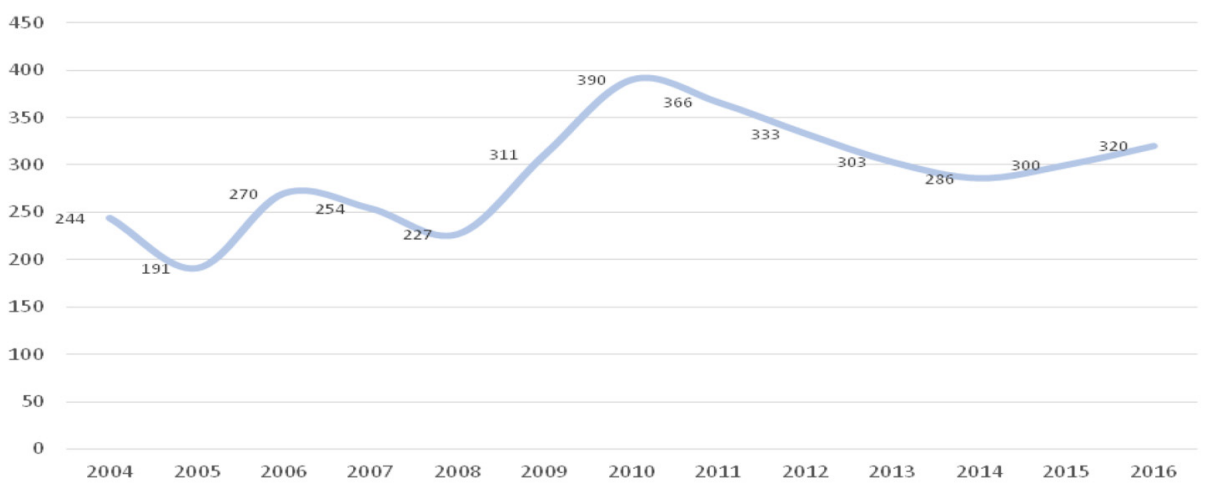

Source: Our elaboration

innovation and network dynamics

Figure 1.

The evolution of patents in Florence 2004-2016

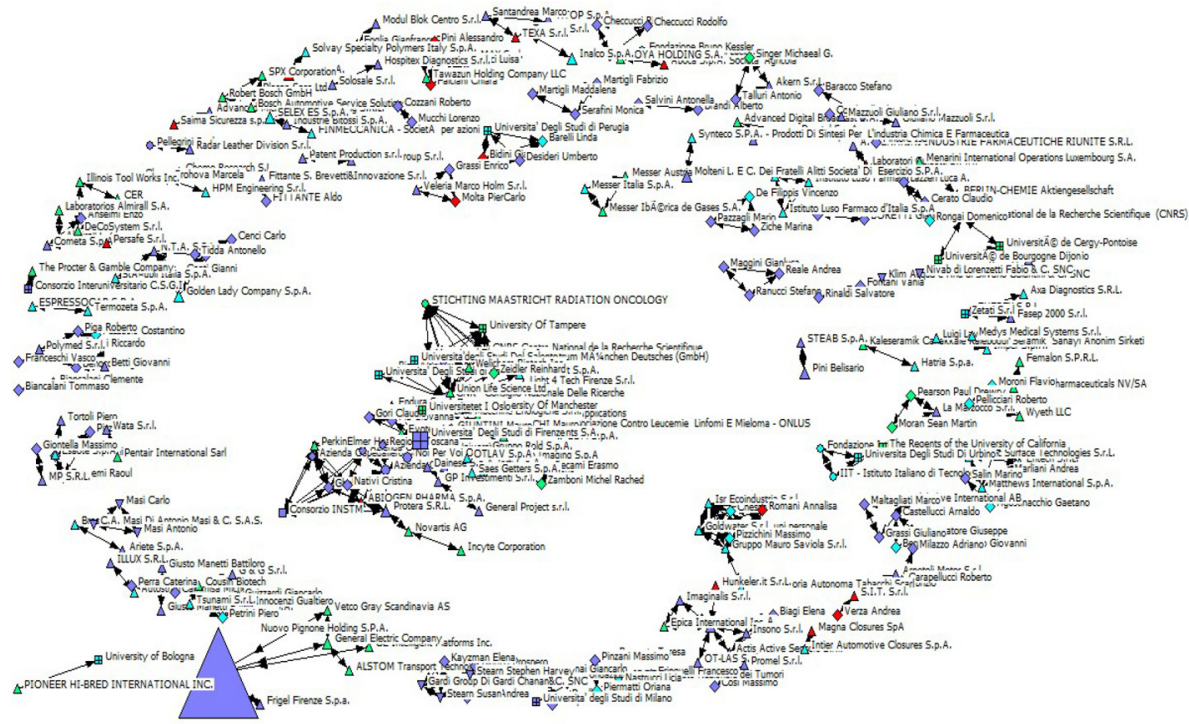

Legend: Shape for typology: Up triangle: limited liability company,Down triangle: partnership/individual firm, diamond: individual inventor, Crossed box: university, Box: consortium, Circle: others. Colours for localisation: Purple: Florence, Azure: Italy, Red: Tuscany; Green: Europe Source: Our elaboration

Figure 2. The invention networks for copatenting in Florence 2004-2016

Finally, through a NBR, we analysed the impact of the characteristics of the openness of the organisation's innovation process for the period 2004-2010 and how the breadth and depth of the openness influence the patent productivity in the following period (2011-2016). The two periods were chosen to avoid problems of causal ambiguity. 


\section{$\mathrm{CR}$ 30,4}
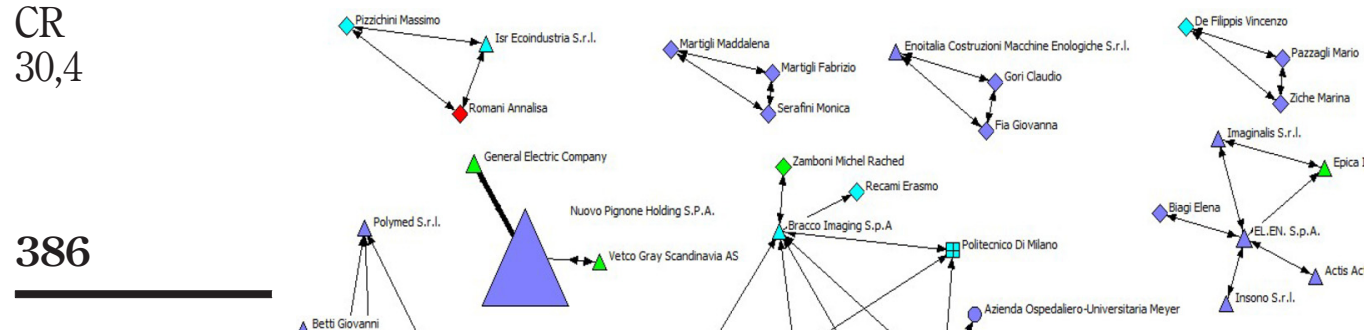

Figure 3.

The invention networks for copatenting in Florence 2004-2016
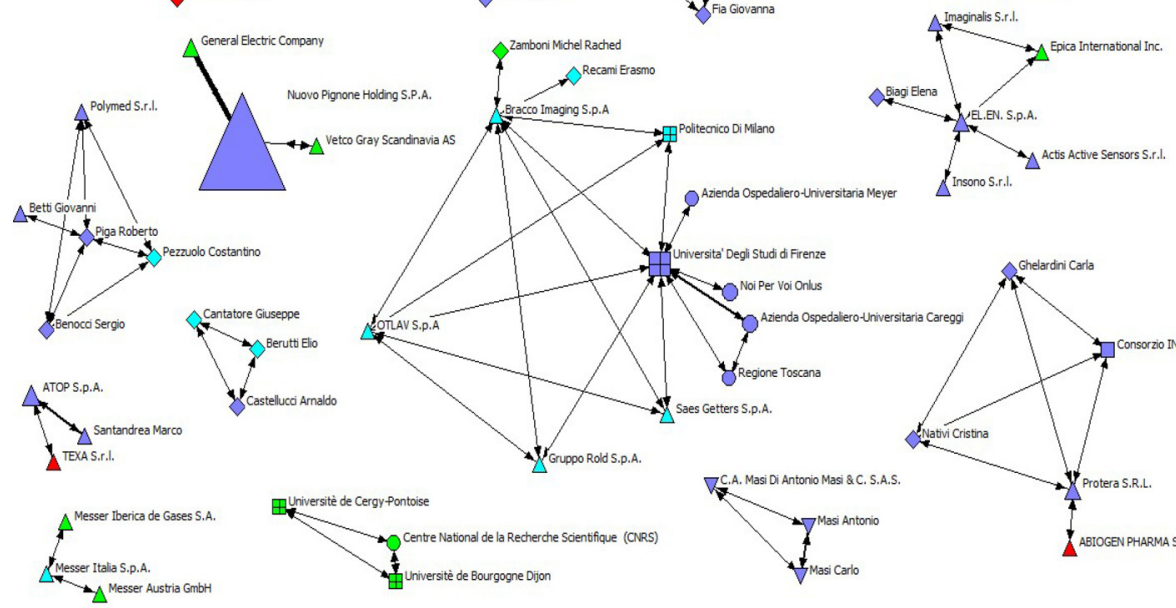

Legend: See Figure 2

Source: Our elaboration

\section{The co-patenting invention networks in Florence}

The first information of particular interest concerns the trend of patents over the years (Figure 1): in the year 2010, the patents reached their maximum number but then decreased in the following years. Values fluctuate around the mean (286) in the period. Unfortunately, it was not possible to go beyond the year 2016 because the number of patents was identified based on the priority date, that is, the date on which the patent was requested by the applicant, from which a period of 24 months may occur before the patent becomes effective; therefore, only partial data are present for the past two years (2017-2018).

We then analysed the invention networks in Florence through a graphical representation of the overall network of applicants (organisation and individual persons) for the realisation of patents for the period 2004-2016.

The study of the relationships among firms, universities, research centres and other organisations was developed using the social network analysis to evaluate the openness of the innovative process of the various actors, establishing whether - and to what extent they have adopted an OI approach. In fact, it is possible to analyse the structure of the networks, how relationships are constructed, how deep they are and the role played by each subject within the individual networks.

Figure 2 shows the network of applicants with at least one co-patenting activity. The nodes represent the different organisations, while the thickness of the ties indicates the number of patents co-produced by two organisations, which measures the intensity of the relationship. Finally, the size of the nodes is related to the number of patents made by each individual organisation.

For a better visualisation of the invention network, Figure 3 shows the collaborations between pairs of organisations with more than three co-patents, highlighting the nonoccasional and more frequent collaborations. 
The most interesting result so far is the emergence of several sub-networks, of which, the most structured is that of the University of Florence (in the centre of Figure 2). In addition, worthy of mention is the presence of the open network of some large companies (El. En, for example) which is related to the development of several patents (78), all with other companies located in the Province of Florence.

The various networks refer mainly to the metropolitan area of Florence (purple nodes), particularly involving firms, but also individual inventors, non-profit organisations, research centres and so forth. The European players (green nodes) have few connections, those with General Electric Nuovo Pignone, which relies mainly with actors located in Europe, develops invention mainly within the boundaries of the firm, according to the closed innovation paradigm. It is the biggest node on Figure 2 (bottom left), with around 500 patents realised within the boundaries of the firm.

\section{An analysis of the openness of the invention network in Florence Operationalisation of the variables}

The purpose of this section is to analyse the impact of the openness of the invention process of the different organisations participating in the invention networks. For the purpose of regression analysis, different types of variables were used, as follows:

- The openness of the organisation invention process represents how often the organisation resorted to external collaborations for the production of patents, which show how open it has been to external sources for the invention process.

The variable is measured as the share of patents realised through collaboration with external actors and was calculated as the ratio between the number of patents made with external sources and the total number of patents developed by each actor.

- The breadth and depth of the openness, which, respectively, indicate the breadth and depth of the opening of the invention process in terms of the number of external partners with which an organisation collaborates for the realisation of patents and the number of relationships maintained with each individual partner. Regarding breadth and depth, Laursen and Salter (2006) defined breadth as the breadth of external research in terms of a variety of partners and depth by the intensity of the collaborations with those external partners. Also, other works follow a similar approach (Hwang and Lee, 2010; Chen et al., 2011).

In the present study, we followed a social network analysis perspective and calculated the breadth and depth based on the structure of the invention networks. The breadth variable was calculated as the sum of the number of external actors with which patents are realised, that is, the number of co-patenting organisations. The variable depth was calculated as the average of the number of co-patents developed with an external co-patenting organisation. For example, if an organisation realises 20 co-patents with five different partners, the subject presents a depth value of four and a breath of five.

- The betweenness (Freeman, 1979) examines the extent to which an actor is between all other actors within the network. Burt (1992) pointed out that having high betweenness, which is highly correlated with having many structural holes, could bring benefits to the central actor; it is connected to the ability of an organisation to act as an intermediary between other subjects. It expresses the potential of a network node in the control of communication. Here, the greater the centrality-betweenness, the greater the role of the actor's connector acting as a broker to unite and relate other unrelated nodes will be. 
$\mathrm{CR}$ 30,4

Finally, some control variables were added to the models. The first set of controls are dummy variables concerning the location of companies (Florence, Tuscany, Italy, Europe), while the second set regard the type of actor (limited liability companies, partnerships, universities) to verify the possible influence they may have on the organisation's ability to innovate.

Table 1 shows the descriptive statistics and the correlations among the variables included in the model.

\section{Results of the analysis}

The dependent variable of the study is the total number of patents realised by an organisation in the period 2011-2016. The characteristics of the dependent variable (discrete and non-negative) require the use of estimation methods appropriate for count data (Hausman et al., 1984) and thus fall in the area of the Poisson family. In addition, the strong variability of the number of patents between provinces called for additional tests on the over-dispersion of the dependent variable. Hence, we conducted a likelihood ratio test, as reported at the bottom of each model; these tests clearly indicated the NBR may be expected to perform better than the Poisson estimator (Greene, 2003).

Table 2 contains the results of the NBR analysis, which was based on 269 observations and that constitute only the organisations[4], that have realised a patent in the two periods (2004-2010 and 2011-2016)

Four different models were used. The first one includes only the variables of the opening of the invention process (openness, breadth and depth). In the second model, the betweenness variable related to the relational behaviour of the actors was also tested. The third and fourth models aimed to evaluate any U-shaped trends of the degree of openness on the ability to innovate, as highlighted in the literature review. For this purpose, the squared values of the variables' breadth and depth were included. In this case, the variables were first scaled and then squared to reduce any collinearity that may occur in the same model when the original variables and their squared values are included. The third model was a replication of the first one with the addition of the squared terms of the breadth and depth, while the last model (Model 4) was also given the variable related to the betweenness. Each of the models included the dummy variables related to the location and typology of the actor involved (corporations, partnerships or universities).

Because multi-collinearity may be an issue, particularly in the last two models where the squared values were included, we conducted a variance-inflation factor (VIF) test for the covariates to detect any multi-collinearity. All the tests conducted and reported at the bottom of each model show values largely below the threshold of 10 (Neter et al., 1990), suggesting that multi-collinearity is not an issue in these cases (the highest VIF mean is 5.2 in our analysis, and the VIF max is 7.1)[5].

The results reported in Table 2 show that the openness of the actors is significant and negative throughout all the models, indicating that a higher degree of openness negatively affects the ability to realise patents. This could be seen as an unexpected result, but it highlights that a generic openness in terms of the share of patents realised with external actors, irrespective of other characteristics, does not necessarily foster the inventive productivity of organisations.

Interestingly, when analysing the other characteristics of the openness of the organisations' innovation process, they show different results. The breadth is significant and positively influences the propensity to innovate; this indicates that developing relationships with many external actors increases the invention capacity of companies. The same effect is shown by the variable depth, which is significant and positive, underlining that developing deep and lasting relationships with the external partners allows for the realisation of a higher number of inventions. This aspect can also create trust among local 


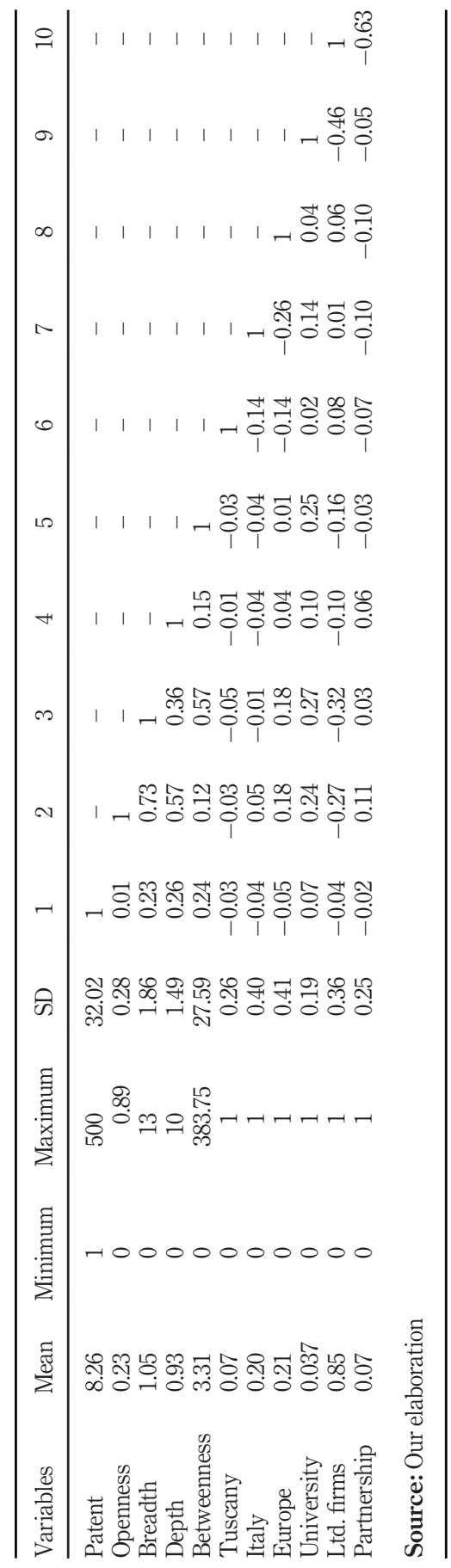

innovation and network dynamics

389

Table 1.

Descriptive statistics and correlation matrix 


\begin{tabular}{|c|c|c|c|c|c|}
\hline \multirow{5}{*}{$\begin{array}{l}\text { CR } \\
30,4\end{array}$} & Variables & Model 1 & Model 2 & Model 3 & Model 4 \\
\hline & Openness & $-2.442^{\text {**** }}(0.476)$ & $-2.901^{* * *}(0.445)$ & $-3.535^{* * *}(0.365)$ & $-3.574^{* * *}(0.359)$ \\
\hline & Breadth & $0.394^{\text {**** }}(0.078)$ & $0.511^{* * * *}(0.073)$ & $0.701^{\text {**** }}(0.077)$ & $0.677^{* * * * *}(0.074)$ \\
\hline & Depth & $0.436^{* * *}(0.081)$ & $0.441^{* * *}(0.070)$ & $0.549^{* * * *}(0.061)$ & $0.577^{* * *}(0.064)$ \\
\hline & Breadt $^{2}$ & - & - & $-0.153^{* * *}(0.023)$ & $-0.127^{* * * *}(0.027)$ \\
\hline \multirow{17}{*}{390} & Depth $^{2}$ & - & - & $-0.079^{* * * *}(0.015)$ & $-0.087^{* * *}(0.016)$ \\
\hline & Betweenness & - & $-0.010^{* * *}(0.003)$ & & $-0.003(0.002)$ \\
\hline & Tuscany & $-0.116(0.232)$ & $-0.127(0.231)$ & $-0.082(0.234)$ & $-0.088(0.235)$ \\
\hline & Italy & $-0.008(0.178)$ & $-0.009(0.177)$ & $-0.037(0.187)$ & $-0.034(0.187)$ \\
\hline & Europe & $-0.327^{*}(0.140)$ & $-0.352 *(0.138)$ & $-0.208(0.141)$ & $-0.225(0.143)$ \\
\hline & University & $0.075(0.731)$ & $0.237(0.298)$ & $0.239(0.260)$ & $0.270(0.269)$ \\
\hline & Limited liability firms & $0.025(0.269)$ & $0.058(0.258)$ & $0.043(0.269)$ & $0.053(0.269)$ \\
\hline & Partnership & $-0.175(0.267)$ & $-0.151(0.252)$ & $-0.120(0.268)$ & $-0.107(0.267)$ \\
\hline & Constant & $1.452^{* * * *}(0.271)$ & $1.417^{* * * *}(0.261)$ & $1.415^{* * * *}(0.288)$ & $1.404^{* * *}(0.285)$ \\
\hline & Lnalpha & $-0.892^{* * * *}(0.222)$ & $-0.999^{* * * *}(0.245)$ & $-1.231^{* *}(0.384)$ & $-1.238^{* *}(0.387)$ \\
\hline & Log Likelihood & -709.5 & -701.3 & -684.4 & -684.1 \\
\hline & Mc Fadden's $R^{2}$ & 0.165 & 0.174 & 0.194 & 0.195 \\
\hline & LR test on overdispersion & $1322.3^{\text {***** }}$ & $695.8^{* * * *}$ & $363.3^{* * * *}$ & $347.12^{* * *}$ \\
\hline & AIC & 1441.0 & 1426.7 & 1394.9 & 1396.3 \\
\hline & $\mathrm{BIC}$ & 1480.6 & 1469.8 & 1441.6 & 1446.6 \\
\hline & VIF Mean & 2.25 & 2.82 & 4.51 & 5.21 \\
\hline & VIF Max & 3.15 & 4.17 & 6.39 & 7.11 \\
\hline \multirow{2}{*}{ Table 2.} & Obs. & 269 & 269 & 269 & 269 \\
\hline & \multicolumn{5}{|c|}{ Notes: Legend: standard errors in parenthesis. Significance: $* * * 0.001 ; * * 0.01 ; * 0.05$} \\
\hline
\end{tabular}

organisations and therefore improve local collaborations and the invention performance of the organisations.

Therefore, if "generic" openness does not appear to be a positive determinant for the invention capacity of the organisations, the depth and breadth of the openness instead positively influence the realisation of patents. It is also important to note that a generic openness shows only a propensity to develop patents with others, here without considering the internal resources and capability needed to innovate (Cohen and Levinthal, 1990).

Regarding the other variables, betweenness is significant and negatively affects the ability to produce patents in Model 2, but it becomes insignificant in Model 4, so it does not appear to play a connecting role between organisations as a way to allow an actor to be more innovative. Finally, the dummies concerning the location and typology of organisations show no significant results in the models. Except for the Europe variable, which shows significant and negative results in the first two models; this variable is strongly driven by the few large companies, which tend to pursue a more closed innovation process, except for the few extra national linkages. As a result, there is no evidence regarding the relationship between the geographical location of the actors and their ability to innovate. Even if we analysed a sample that gravitates more towards the metropolitan area of Florence, collaborations could be developed also with external actors, so pairing only with local actors does not seem to make a difference. The same consideration can be made for the typology of organisations, which is not significant in the various models.

Finally, regarding the nonlinearity issues of the openness investigated in the last two models, the breadth variable positively influences patent productivity, much like in Models 1 and 2 ; however, the squared values (breadth ${ }^{2}$ ) turn out to be (significant and) negative. This result implies that the breadth of the openness, which is measured by the number of external co-applicants with which every single subject creates patents, beyond a certain point will negatively affect the ability to innovate. 
From Figure 4(a), the breadth is not linearly related to the patents' productivity, but it assumes a U-inversed curvilinear pattern. There is a "tipping point" beyond which the number of organisations with which an actor collaborates negatively affects the capacity to innovate. This limit is identified in six patent collaborations for the analysed case (for the period 2004-2011). Increasing the number of partners improves the invention performance of an organisation until reaching an optimal number of collaborations, after which adding in more companies becomes counterproductive.

Also, regarding depth, we reached similar conclusions; in fact, the results of the analysis

Open

innovation and network dynamics indicate a positive and significant coefficient for the original variable, while the depth ${ }^{2}$ results are negative and significant. Much like the results obtained regarding the breadth, the intensity of the relationships with external sources of knowledge shows a U-inversed relation to the invention productivity. The tipping point for the intensity of the relationships is six, beyond which the returns in terms of inventions tend to decrease [Figure 4(b)]. As a result, an organisation with less than six relationships with a co-applicant for the period 2004-2010 will tend to develop a higher patent productivity for the period 2011-2016.

In conclusion, the results show that within a certain limit, breadth and depth are positively correlated with the patent productivity of organisations. Beyond a certain level, they generate a negative impact on the innovative performance of the actors[6].

\section{Conclusions}

The results allow us to positively confirm the hypotheses regarding the existence of a relationship between the opening of a firm's innovation process and the capacity to innovate. However, the first hypothesis is the only one not confirmed, indicating that just collaborating with others when producing a patent is negatively correlated with the invention productivity of the organisation. The most interesting hypothesis regarding the breadth and depth of openness is confirmed, indicating that breadth and depth are positively correlated with invention productivity $(H 2)$ and that they have a curvilinear relation (taking an inverted $\mathrm{U}$ shape) with invention productivity $(H 3)$.

Specifically, the current study determined quite similar evidence compared with the result of Laursen and Salter (2006). Indeed, Laursen and Salter (2006) showed that the external search breadth and the external search depth assume a U-inversed trend compared with the innovative performance. In particular, within a certain limit, breadth and depth are positively correlated with innovative performance. Beyond a certain limit, they generate a negative impact on the innovative performance of the company. However, our approach

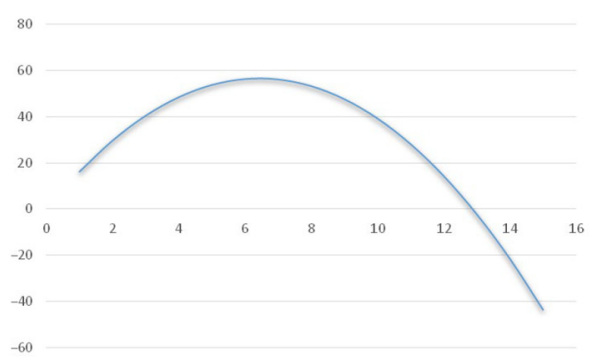

(a)

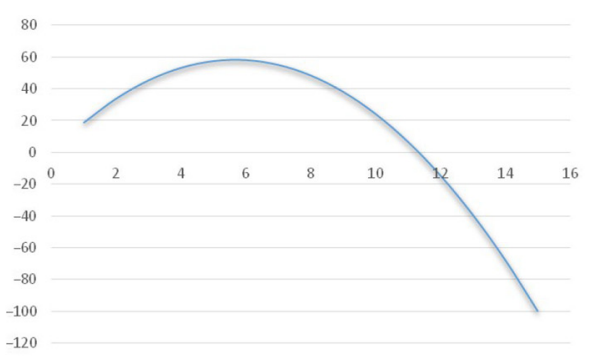

(b)
Figure 4. Breadth, depth and invention productivity

Notes: (a) Breadth and inventions; (b) depth and inventions

Source: Our elaborations 
$\mathrm{CR}$ 30,4

focusses on the effective relationships' activities of firms in producing new patents, while most previous works were mainly concentrated on how using different sources of knowledge, as a proxy of openness, helps to produce inventions. This is a novelty of our work.

In this context, our study confirmed the same impact of the breadth and depth of the opening of the invention process on firms' invention capacity. In particular, a tipping point was identified for the breadth variable and for the depth one.

The results achieved are in line also with those obtained by Love et al. (2014), who suggested that the opening of the innovative process could represent two advantages for companies: openness increases the innovative performance in the current period and provides a basis for learning effects, which increases the innovative performances derived from future openness.

In the empirical analysis carried out, the firms that - within the limits described previously - adopted an open approach to innovation also improved their innovative performances, and this can be explained in part by a greater level of absorptive capacity.

These results are useful for drawing up some managerial and policy implications; managers should evaluate their environment and their firm's relational capabilities to maximise firm performance and reduce costs and waste. In addition, they should carefully evaluate how to open their innovation process; here, it is not the mere increase of collaborations that favours innovation performances. Managers should design their innovation strategies by focussing on the quality of the relations (depth) that may favour the growth of trust and routines between actors and on having a fair number of collaborations (breadth) that may enhance the acquisition of external knowledge.

In this vein, the results may help draw some suggestions for policy-makers when it comes to favouring the innovativeness of the area; the evidence clearly shows that it is not just a matter of increasing the number of collaborations among actors to favour the innovativeness. Instead, it is relevant to take into account both the number of realised collaborations and at the same time, the presence of a certain degree of previous collaborations between the involved actors. However, what seems to be crucial is to consider the curvilinear effect of these two forces and hence avoiding too large partnerships and too consolidated relations that may lead to lock-in.

This research also presents some limitations. First, the number of patents created by the organisation was used as a proxy for the innovative performance of companies. The patents, however, can only identify the codified innovation, not all the innovation outputs, both formal and informal, of the companies (R\&D projects, research collaborations, etc.). The analysis carried out was limited only to some aspects of the opening of the innovation process; therefore, it would be interesting and useful to extend the research to obtain a broader picture of the effects of the openness of firms' innovation processes.

Second, the PAT-STAT database does not uniquely recognise individual inventors. For this reason, we chose to analyse the applicant network rather than the inventor network.

Third, the current research has focussed on a narrow territorial context: the metropolitan area of Florence. To overcome this, future research could expand the empirical analysis to a wider level, such as the whole of Italy or also other European countries.

In addition, an interesting point for further research could be to include the innovative capacity of firms, for example, the share of turnover deriving from new products or R\&D expenses. This would establish whether openness is also related to some internal characteristics of the firms and how this is related to their relational behaviours.

Notwithstanding the limits of this research, the results are interesting because they have shown that how relational activities that are implemented affect the openness of the innovation process and influence the capacity of firms to innovate. 


\section{Notes}

1. See, for instance, Pezzoni et al. (2014) or Innocenti et al. (2019) or the debate in Ventura et al. (2015).

2. We refer, for instance, to the case of a mistake in the name like "GE Nuovo Pignone" or "Nuovo Pingnone" or "Nuovo Pignone GE". All the patents then had to be verified one by one.

3. In the regression, inventors as applicants have been deleted to investigate open innovation practices; in the following graphs, applicants as individual persons are maintained to point out the organisations' relational behaviour.

4. As underlined in the previous section, in regression analysis applicants as individual persons were omitted to investigate organisations' open innovation practices.

5. However, owing to a quite high level of correlation between openness and breadth and depth, we did an additional robustness check, testing the openness in a separate model and then breadth and depth in one other model reported in Table 3 of the Appendix. As the results did not substantially change, we decided to go on with the complete models.

6. As a robustness check, an estimation was also developed for the years 2010-2016 and presents the same results achieved with the previous analysis. In addition, the results are consistent also when including individual inventors as applicants. We include this last analysis in the Appendix.

\section{References}

Acs, Z., Anselin, L. and Varga, A. (2002), "Patents and innovation counts as measures of regional production of new knowledge", Research Policy, Vol. 31 No. 7, pp. 1069-1085.

Alberti, F. and Pizzurno, E. (2015), "Knowledge exchanges in innovation networks: evidences from an Italian aerospace cluster", Competitiveness Review, Vol. 25 No. 3, pp. 258-287.

Antonietti, R. and Gambarotto, F. (2018), "The role of industry variety in the creation of innovative start-ups in Italy”, Small Business Economics, Vol. 54 No. 2, pp. 561-573.

Bathelt, H., Malmberg, A. and Maskell, P. (2004), "Clusters and knowledge: local buzz, global pipelines and the process of knowledge creation", Progress in Human Geography, Vol. 28 No. 1, pp. 31-56.

Belussi, F. and Orsi, L. (Eds) (2015), Innovation, Alliances, and Networks in High-Tech Environments, Routledge.

Belussi, F., Sammarra, A. and Sedita, S. (2010), "Learning at the boundaries in an 'open regional innovation system': a focus on firms' innovation strategies in the emilia romagna life science industry", Research Policy, Vol. 39 No. 6, pp. 710-721.

Brunswicker, S. and Van De Vrande, V. (2014), "Exploring open innovation in small and medium-sized enterprises", in Chesbrough H., Vanhaverbeke W. and West J. (Eds), New Frontiers in Open Innovation, Oxford University Press. Oxford.

Burt, S. (1992), Structural Holes: The Social Structure of Competition, Harvard University Press, Cambridge, MA.

Capone, F. and Zampi, V. (2019), "Proximity and centrality in inter-organisational collaborations for innovation", Management Decision, Vol. 58 No. 2, pp. 239-254.

Capone, F., Lazzeretti, L. and Innocenti, N. (2019), "Innovation and diversity: the role of knowledge networks in the inventive capacity of cities", Small Business Economics, Vol. 1, doi: 10.1007/ s11187-019-00268-0.

Capone, F., Zampi, V. and Innocenti, N. (2018), "How do R\&D project networks support the adoption of open innovation practice?”, Sinergie Italian Journal of Management, Vol. 106, pp. 23-40.

Chen, J., Chen, Y. and Vanhaverbeke, W. (2011), "The influence of scope, depth, and orientation of external technology sources on the innovative performance of chinese firms", Technovation, Vol. 31 No. 8, pp. 362-373. 
$\mathrm{CR}$ 30,4

Chesbrough, H. (2003), Open Innovation, the New Imperative for Creating and Profiting from Technology, Harvard Business School Press, Boston.

Chesbrough, H. (2006), Open Business Models: How to Thrive in the Innovation Landscape, Harvard Business School Press, Boston.

Chiang, Y. and Hung, K. (2010), "Exploring open search strategies and perceived innovation performance from the perspective of interorganizational knowledge flows", $R \& D$ Management, Vol. 40 No. 3, pp. 292-299.

Chiaroni, D., Chiesa, V. and Frattini, F. (2011), "The open innovation journey: how firms dynamically implement the emerging innovation management paradigm”, Technovation, Vol. 31 No. 1, pp. 34-43.

Cohen, W. and Levinthal, D. (1990), "Absorptive capacity: a new perspective on learning and innovation”, Administrative Science Quarterly, Vol. 35 No. 1, pp. 128-152.

Cooke, P. (2005), "Regionally asymmetric knowledge capabilities and open innovation: exploring 'globalisation 2' - a new model of industry organisation", Research Policy, Vol. 34 No. 8, pp. 1128-1149.

D'Ambrosio, A., Gabriele, R., Schiavone, F. and Villasalero, M. (2017), "The role of openness in explaining innovation performance in a regional context", The Journal of Technology Transfer, Vol. 42 No. 2, pp. 389-408.

Dahlander, L. and Gann, D. (2010), "How open is innovation?", Research Policy, Vol. 39 No. 6, pp. 699-709.

De Noni, I., Ganzaroli, A. and Orsi, L. (2017), "The impact of intra-and inter-regional knowledge collaboration and technological variety on the knowledge productivity of European regions", Technological Forecasting and Social Change, Vol. 117, pp. 108-118.

Di Minin, A. and Rossi, M. (2016), "Open innovation and clusters: why geographical proximity matters", in Revolutionising EU Innovation Policy, Palgrave Macmillan, London, pp. 79-95.

Dittrich, K. and Duysters, G. (2007), "Networking as a means to strategy change: the case of open innovation in mobile telephony", Journal of Product Innovation Management, Vol. 24 No. 6, pp. $510-521$.

Enkel, E. (2010), "Attributes required for profiting from open innovation in networks", International Journal of Technology Management, Vol. 52 No. 3/4, pp. 344-371.

Enkel, E. and Bader, K. (2013), "How to balance open and closed innovation: strategy and culture as influencing factors", in Tidd, J. (Ed.), Open Innovation Research, Management and Practice, Imperial College Press, London, pp. 87-104.

Ejermo, O. and Karlsson, C. (2006), "Interregional inventor networks as studied by patent coinventorships", Research Policy, Vol. 35 No. 3, pp. 412-430.

Ferraris, A., Santoro, G. and Bresciani, S. (2017), "Open innovation in multinational companies' subsidiaries: the role of internal and external knowledge", European J. Of International Management, Vol. 11 No. 4, pp. 452-468.

Ferreras-Méndez, J., Newell, S., Fernández-Mesa, A. and Alegre, J. (2015), "Depth and breadth of external knowledge search and performance: the mediating role of absorptive capacity", Industrial Marketing Management, Vol. 47, pp. 86-97.

Freeman, L. (1979), “Centrality in social networks: conceptual clarification”, Social Networks, Vol. 1, pp. 215-239.

Giusti, J., Alberti, F. and Belfanti, F. (2018), "Makers and clusters. knowledge leaks in open innovation networks", Journal of Innovation and Knowledge, Vol. 5 No. 1, pp. 20-28.

Greco, M., Grimaldi, M. and Cricelli, L. (2015), "Open innovation actions and innovation performance: a literature review of European empirical evidence", European Journal of Innovation Management, Vol. 18 No. 2, pp. 150-171. 
Greene, M. (2003), Econometric Analysis, Prentice Hall, New York, NY.

Hausman, J., Hall, B. and Griliches, Z. (1984), "Econometric models for count data with an application to the patents-R\&D relationship", Econometrica, Vol. 52 No. 4, pp. 909-938.

Henkel, J. (2009), "Champions of revealing. The role of open source developers in commercial firms", Industrial and Corporate Change, Vol. 18 No. 3, pp. 435-471.

Open

innovation and

network

dynamics

Herzog, P. and Leker, J. (2010), "Open and closed innovation: different innovation cultures for different strategies”, International Journal of Technology Management, Vol. 52 Nos 3/4, pp. 322-343.

Huang, F. and Rice, J. (2013), “Does open innovation work better in regional clusters?”, Australasian Journal of Regional Studies, Vol. 19 No. 1, pp. 85-120.

Huizingh, E. (2011), "Open innovation: state of the art and future perspectives”, Technovation, Vol. 31 No. 1, pp. 2-9.

Hwang, J. and Lee, Y. (2010), "External knowledge search, innovative performance and productivity in the korean ICT sector", Telecommunications Policy, Vol. 34 No. 10, pp. 562-571.

Innocenti, N., Capone, F. and Lazzeretti, L. (2020), "Knowledge networks and industrial structure for regional innovation: an analysis of patents collaborations in Italy", Papers in Regional Science, Vol. 99 No. 1, pp. 55-72, doi: 10.1111/pirs.12478.

Jarvenpaa, S. and Wernick, A. (2011), "Paradoxical tensions in open innovation networks", European Journal of Innovation Management, Vol. 14 No. 4, pp. 521-548.

Knudsen, M. and Mortensen, T. (2011), "Some immediate - but negative - effects of openness on product development performance", Technovation, Vol. 31 No. 1, pp. 54-64.

Kovacs, A., Van Looy, B. and Cassiman, B. (2015), "Exploring the scope of open innovation: a bibliometric review of a decade of research", Scientometrics, Vol. 104 No. 3, pp. 951-983.

Laursen, K. and Salter, A. (2006), "Open for innovation: the role of openness in explaining innovation performance among UK manufacturing firms", Strategic Management Journal, Vol. 27 No. 2, pp. 131-150.

Laursen, K. and Salter, A.J. (2014), "The paradox of openness: appropriability, external search and collaboration”, Research Policyam, Vol. 43 No. 5, pp. 867-878.

Lazzarotti, V. and Manzini, R. (2014), "Different modes of open innovation a theoretical framework and an empirical study", International Journal of Innovation Management, Vol. 13 No. 04, pp. 615-636.

Lee, S., Park, G., Yoon, B. and Park, J. (2010), "Open innovation in SMEs. An intermediated network model”, Research Policy, Vol. 39 No. 2, pp. 290-300.

Love, J., Roper, S. and Vahter, P. (2014), "Learning from openness: the dynamics of breadth in external innovation linkages", Strategic Management Journal, Vol. 35 No. 11, pp. 1703-1716.

Martinez-Torres, M. (2014), "Analysis of open innovation communities from the perspective of social network analysis”, Technology Analysis and Strategic Management, Vol. 26 No. 4, pp. 435-451.

Martinez, M., Lazzarotti, V., Manzini, R. and Sánchez García, M. (2014), "Open innovation strategies in the food and drink industry”, International Journal of Technology Management, Vol. 66 Nos 2/3, pp. 212-242.

Malmberg, A. and Maskell, P. (2006), “Localized learning revisited”, Growth and Change, Vol. 37 No. 1, pp. 1-18.

Mortara, L. and Minshall, T. (2011), "How do large multinational companies implement open innovation?”, Technovation, Vol. 31 No. 10-11, pp. 586-597.

Neter, J., Wasserman, W. and Kunter, M. (1990), Applied Linear Statistical Models: Regression, Analysis of Variance, and Experimental Design, Irwin, Homewood.

Parida, V., Westerberg, M. and Frishammar, J. (2012), "Inbound open innovation activities in high-tech SMEs: the impact on innovation performance", Journal of Small Business Management, Vol. 50 No. 2, pp. 283-309. 
$\mathrm{CR}$

30,4

Pezzoni, M., Lissoni, F. and Tarasconi, G. (2014), "How to kill inventors: testing the massacrator` algorithm for inventor disambiguation", Scientometrics, Vol. 101 No. 1, pp. 477-504.

Porter, M. (1998), "Clusters and the new economics of competition", Harvard Business Review, Vol. 76 No. 6, pp. 77-90.

Powell, W. and Grodal, S. (2005), "Networks of innovators", in Fagerberg J., Mowery D.C. and Nelson R. R. (Eds), The Oxford Handbook of Innovation, Oxford University Press, Oxford, pp. 56-85.

Powell, W., Koput, K. and Smith-Doerr, L. (1996), "Interorganizational collaboration and the locus of innovation: networks of learning in biotechnology", Administrative Science Quarterly, Vol. 41 No. 1, pp. 116-145.

Scott, J. (2011), Social Network Analysis, Sage, New York, NY.

Simard, C. and West, J. (2006), "Knowledge networks and the geographic locus of innovation", in Chesbrough, H., Vanhaverbeke, W. and West, J. (Eds), Open Innovation: Researching a New Paradigm, Oxford University Press, Oxford, pp. 220-240.

Tallman, S., Jenkins, M., Henry, N. and Pinch, S. (2004), "Knowledge, clusters, and competitive advantage", Academy of Management Review, Vol. 29 No. 2, pp. 258-271.

Ter Wal, A. (2014), "The dynamics of the inventor network in german biotechnology: geographic proximity versus triadic closure", Journal of Economic Geography, Vol. 14 No. 3, pp. 589-620.

Trott, P. and Hartman, D. (2009), "Why 'open innovation' is old wine in new bottles”, International Journal of Innovation Management, Vol. 13 No. 4, pp. 715-736.

Vanhaverbeke, W. (2006), "The inter-organizational context of open innovation", in Chesbrough, H., Vanhaverbeke, W. and West, J. (Eds.), Open Innovation: Researching a New Paradigm, Oxford University Press, Oxford.

Vanhaverbeke, W., Chesbrough, H. and West, J. (2014), "Surfing the new wave of open innovation research", in Chesbrough, W., Vanhaverbeke, H.W. and West, J. (Eds), New Frontiers in Open Innovation, Oxford University Press, Oxford, pp. 281-294.

Ventura, S., Nugent, R. and Fuchs, E. (2015), "Seeing the non-stars: (some) sources of bias in past disambiguation approaches and a new public tool leveraging labeled records", Research Policy, Vol. 44 No. 9, pp. 1672-1701.

\section{Further reading}

Capone, F. and Lazzeretti, L. (2018), "The different roles of proximity in multiple informal network relationships. Evidence from the cluster of high technology applied to cultural goods in tuscany", Industry and Innovation, Vol. 25 No. 9, pp. 897-917.

Fichter, K. (2009), "Innovation communities: the role of networks of promoters in open innovation", R\&D Management, Vol. 39 No. 4, pp. 357-371.

Wincent, J., Anokhin, S. and Boter, H. (2009), "Network board continuity and effectiveness of open innovation in swedish strategic small-firm networks", R\&D Management, Vol. 39 No. 1, pp. 55-67.

\section{Corresponding author}

Niccolò Innocenti can be contacted at: niccolo.innocenti@unifi.it

For instructions on how to order reprints of this article, please visit our website:

www.emeraldgrouppublishing.com/licensing/reprints.htm

Or contact us for further details: permissions@emeraldinsight.com 